\title{
Mediating Role of Synergy Effect of Merger and Acquisition in the Influence of Competitive Behavior on Enterprise Performance
}

\author{
Liangjun $\mathrm{He}$ \\ School of Economics and Management \\ Beihang University \\ Beijing, China
}

\author{
Xinyi Ma \\ Accounting School \\ Nanfang College of Sun Yet-Set University \\ Guangzhou, China
}

\author{
Shenglei $\mathrm{Pi}^{*}$ \\ School of Management \\ Guangzhou University \\ Guangzhou, China \\ pishenglei@126.com
}

\begin{abstract}
China's market segmentation has led to companies facing national and regional competition in domestic market after merger and acquisition. This paper adopts empirical study to explore the mediating role of synergy in the influence of competitive behavior on performance after Chinese enterprises mergers and acquisitions. The study finds that the complexity of the national competition strategy has positive impact on enterprise performance, while the regional competition inertia has a significant positive effect on enterprise performance. Operational synergy plays a full mediating role in the influence of competition strategy complexity on enterprise performance at the national level. At the same time, operational synergy, sales synergy and financial synergy have a complete mediating effect on regional competition inertia. Operational synergy has the greatest impact on enterprise performance, reflecting to some extent the resource orientation behind Chinese M\&A activities.
\end{abstract}

Keywords-Merger and Acquisition(M\&A); Competitive behavior; Enterprise performance; Synergy effect; Mediating role

\section{INTRODUCTION}

Since China has joined the WTO, international multinational companies have entered the Chinese market through investment, joint ventures or even mergers and acquisitions. Therefore, an important issue facing Chinese companies is how to enhance their international competitiveness [1,2]. At the national level, companies that have implemented M\&A face competition from companies that have implemented the same or similar M\&A, and taken advantage of multiple points of competition after M\&A [3]; at the regional level, companies that implement M\&A use regional institutional differences and local social capital to defenses against the attacks of multinational corporations [4,5] These two levels of competition and two different types of competitors have become the key elements in the evolution of dynamic competitive behavior of Chinese companies today. The current focus of dynamic competition research is the various characteristics of the Competitive Repertoire, but few scholars pay attention to the impact of the management mechanism or mode on the competitive behavior and its effects against the background of the two-level competition pattern of Chinese enterprises. The ultimate goal of M\&A integration is to achieve synergy. Synergy refers to the integration, sharing and optimization of enterprise resources [6], which reflects the comprehensive situation of integrated management mode, structure and mechanism.

This paper discusses the impact of the synergy of enterprise groups on the competition behavior at the national and regional levels after mergers and acquisitions, and then tries to find an integrated management mode in which Chinese enterprises compete effectively at two levels. The content of this paper includes: (1) On the basis of reviewing the relevant theoretical researches after the merger and acquisition, establish the post-acquisition synergy revenue model, and then derive the surrogate indicators for the strategic synergy after the merger; (2) Put forward hypotheses on the influence of enterprise performance by competition and on post-merger strategic synergy as a mediating role in this influence mechanism ; (3) Analyze the news and annual reports of the listed companies from Chinese liquor and air transport industries for 10 years (partially less than 10 years) and conduct empirical verification, and analyze the results of empirical study.

\section{THEORETICAL BACKGROUND AND HYPOTHESES PRESENTATION}

\section{A. Competitive Strategy Portfolio and Enterprise Performance}

Complexity of competition strategy refers to the scope of action differentiation implemented by enterprises [7, 8] and the field of competitive behavior [9]. Competitive inertia 
refers to the flexibility of an enterprise to implement differentiated competitive actions. Reducing the competitive inertia means enhancing organization's ability to execute competitive strategies without relying on a specific strategy [10], so there is a negative correlation between competitive inertia and corporate performance [11]. Some people have emphasized the characteristics of enterprise collaboration, such as the characteristics of the company's executive team [11], the organization's internal information process [12], which will affect the reduction of competitive inertia [8]. Some scholars believe that when companies implement competitive actions in multiple dimensions (such as research and development, marketing, production, and channels), the complexity of their competitive strategy portfolio will increase Western scholars have found that the combination of behavioral differentiation and complexity in corporate strategy portfolio will help companies to obtain a unique competitive advantage [13], which makes competitors unprepared and unable to counterattack [14].

In order to gain a competitive advantage, the M\&A integration enterprises competed at the national level, mainly targeting regional opponents who did not implement integration and implemented similar competitors. After the integration, most of the enterprises fully exerted the scale advantage and multi-point competitive advantages after merger, and established and maintained the ability to control and competitive advantage in each regional market through the overall deployment nationwide. Therefore, after integration, enterprises need to make full use of the resource advantages in the horizontal and vertical directions to improve the complexity of the competition strategy, and use a combination of multiple strategies to establish a competitive advantage for regional enterprises that have not implemented integration. At the same time, for the same kind of opponents, enterprises need to increase their flexibility and ability to use the speed of change to get rid of the rivals' own checks and balances in the horizontal multi-market and vertical supply chain [15]. Therefore, at the national level, the complexity of corporate competition strategy has a positive impact on corporate performance, while the inertia of competition has a negative impact on corporate performance.

On the other hand, at the regional level, whether it is an opponent of its kind or a multinational company, the implementation of horizontal integration enterprises has no absolute advantage in multi-point competition and balance. If enterprises want to use regional social resources or institutional differences to establish regional market barriers or market forces, the inertia of competitive behavior of enterprises should not be too high, because any competitive behavior of enterprises at the regional level needs to be carried out with various social groups or forces in the region. Communicate and even rely on these social resources to implement certain competitive behaviors. After adopting and integrating various social resources, enterprises will adopt different competition strategies. The complexity of the regional competition strategy has increased, indicating that the company the region's social resources the company get is relatively rich, and its regional market power may also be greater, so it is more likely to produce higher performance.
Therefore, at the regional level, competitive inertia and strategic complexity have a positive impact on firm performance.

H1a: The complexity of competition strategy at the national level has a positive effect on corporate performance.

H1b: The inertia of competition at the national level has a negative effect on corporate performance.

H1c: Inertia of competition at the regional level has a positive effect on corporate performance.

H1d: The complexity of the competition strategy at the regional level has a positive effect on corporate performance.

\section{B. Synergy, Competitive Behavior at National Level and Corporate Performance After M\&A}

The resource-based view holds that the integration of economic units is greater than the sum of the values created by the original dispersion, that is, synergy is achieved [16]. Ansoff [17] further proposed that the enterprise integration system includes the synergy of four different links or dimensions: sales synergy, operational synergy, investment synergy and management synergy. Sales Synergy refers to the sales of various products of an enterprise. It can be completed through the same sales management team and system when it can share sales channels, advertisements, promotions and even brands as much as possible. Operating Synergy refers to the effective use of the advantages of efficient use and organizational learning of human resources and facilities in the production and operation of products. Investment Synergy comes from the rational and efficient use of some assets by companies. Management Synergy refers to the sharing and integration of strategic, organizational and operational management activities and capabilities.

The integrated enterprise through M\&A competes at the national level with regional opponents who did not implement integration and competitors of its kind implementing integration. Synergy after mergers and acquisitions will amplify and transform the competitive behavior of enterprises so that they can better serve the performance of enterprises. Therefore, reducing the inertia of competition at the national level and realizing the dynamic nature of competitive behavior will strengthen the requirements of the company's operational synergy and further improve the performance of the enterprise; while increasing the complexity of competition will also promote the integration of vertical resources at the national level. And achieve better cooperation and synergy between the upstream and downstream of the supply chain, thereby promoting performance. Therefore, operational synergy has a mediating role in the complexity of the national competition strategy and the mechanism of competition inertia on performance.

In addition, the sharing and integration of technology, knowledge and resources in multiple regional markets will promote the competitive strategies issued by corporate headquarters, which can be well communicated and implemented in various regional markets, thus ensuring the national uniformity of enterprises. Competition is uniformly deployed in accordance with the plans and instructions of the 
headquarters. The improvement of sales synergy can give play to the strain and flexibility of the company's competitive behavior at the national level, that is, reduce the inertia of national competition. Therefore, sales synergy has a mediating effect on the role of competitive inertia at the national level in performance.

H2a: Operational synergy has a full mediating role between the competitive strategy complexity at the national level and enterprise.

$\mathrm{H} 2 \mathrm{~b}$ : Operational synergy has a full mediating role between competitive inertia at the national level and enterprise performance.

H2c: Sales synergy has a full mediating role between competitive inertia at the national level and enterprise performance.

\section{Synergy, Regional Competition Inertia and Enterprise Performance After M\&A}

According to the discussion above, regional competition inertia has a positive impact on firm performance. The synergy of firms in different dimensions after M\&A will have different effects on this mechanism of influence. Operation synergy mainly reflects the allocation and sharing of resources in the vertical value chain. The different links integrated in the vertical value chain will be more strongly related to the specific regional social environment in which the enterprise integration behavior occurs, and will be affected by the regional environmental dynamics. The increased synergy of vertical or related resources will strengthen the integration of social resources at all levels of the enterprise. Therefore, the increased inertia of the enterprise at the regional level is beneficial to the interaction and learning between the enterprise and the relevant parties in various regions, thus contributing to the improvement of the overall operational synergy of the group. The increase in synergy such as operations can naturally improve performance. Therefore, it can be said that the inertia of competition at the regional level is improved, and it is possible to achieve synergy through performance management.

H3a: Operational synergy has a complete mediating role between regional competition inertia and enterprise performance.

H3b: Sales synergy has a full mediation between regional competition inertia and enterprise performance.

H3c: Management synergy has a complete mediating effect between regional competition inertia and enterprise performance.

H3d: Financial synergy has a complete mediating effect between regional competition inertia and enterprise performance.

\section{STUDY DESIGN}

\section{A. Samples and Data}

This study selected the top listed companies in Chinese air transport and liquor industries (6 air transport and 10 liquor) as samples. Through the Infobank Economic News System, we searched and collected news reports on the competition behaviors of the listed companies of air transport and liquor industries from 2001 to 2010 and used the structural content analysis method[18] for analysis. In the 536 competitions of liquor companies, 156 competitions at various levels were identified; in 842 competitions of air transport companies, 421 competitions at various levels were identified.

\section{B. Variables}

Dependent variable: enterprise performance. This paper selects the return on assets (ROA) as an indicator of enterprise performance.

Independent variables: competitive inertia and the complexity of competitive strategies. Competitive inertia refers to the level of activity exhibited by a company in changing its own competitive actions. This paper follows the measurement methods of Miller and Chen (1994). The complexity of the competition strategy combination refers to the scope of the action differentiation implemented by the enterprise [10]. This paper uses the method of Ferrier et al. (1999)[8] to measure the simplicity of competitive behavior.

Intermediary variables: operating expense ratio, sales expense ratio, management expense ratio and financial expense ratio. The above four indicators are used to indicate the synergy of the four dimensions of business operations, sales, management and finance.

Control variables: The establishment time and resource endowment are the main control variables, in which the capital endowment is represented by three indicators [11]: the size of the enterprise, the operating profit of the enterprise in the current year, and the profit of the previous year. Since the inertia of competition has a deep correlation with the scale of business operations, the operating scale is added as a control variable in the regression model with inertia as the dependent variable.

\section{RESULTS AND CONCLUSIONS}

SPSS16.0 is used for general linear regression analysis to verify the hypotheses, and the analysis results are shown in Table I.

The complexity of the competition strategy at the national level has a significant positive impact on firm performance, while the regional inertia of competition has a significant positive effect on firm performance. Hence, hypotheses H1a and H1c are validated. Through the verification of the mediating effect, it is found that the operational synergy plays a full mediating role in the effect of competition strategy complexity at the national level on performance, i.e., hypothesis $\mathrm{H} 2 \mathrm{a}$ is validated. Operational synergy, sales synergy and financial synergy have a full mediating effect on regional competition inertia. Hence hypotheses $\mathrm{H} 3 \mathrm{a}, \mathrm{H} 3 \mathrm{~b}$ and $\mathrm{H} 3 \mathrm{~d}$ are validated respectively.

Dynamic competitive behavior of enterprises is of great strategic significance to enterprises. The research in this paper finds that due to the emergence of the two-level competition pattern caused by market segmentation, Chinese enterprises 
that have implemented M\&A need to realize dynamic and contingency in the design of integrated management mode. From the perspective of playing competitive behavior, enterprise integration does not necessarily achieve synergy in all dimensions. In the competition at the regional level, how to guarantee and support the improvement of the regional inertia of enterprises has become a very challenging topic in the design management mode of enterprises after M\&A. According to the analysis of this paper, improving the synergy of operation, sales and finance will help enterprises to improve the inertia of regional competition, so as to better utilize regional social resources to play regional competition behavior and resist the attacks from multinational companies and similar competitors to the regional market. At the same time, in terms of management synergy, enterprises can appropriately decentralize and transfer management power to subcompanies in various regions, so that regional sub-subsidiaries have more authority to make quick decisions according to the actual situation in the region.

TABLE I. LINEAR REGRESSION RESULTS

\begin{tabular}{|c|c|c|c|c|c|c|}
\hline & ROA & $\begin{array}{l}\text { Operating } \\
\text { expense ratio }\end{array}$ & $\begin{array}{c}\text { Sales } \\
\text { expense ratio }\end{array}$ & $\begin{array}{lr} & \text { Manageme } \\
\text { nt } & \text { expense } \\
\text { ratio } & \end{array}$ & $\begin{array}{r}\text { Financial } \\
\text { expense ratio }\end{array}$ & ROA \\
\hline \multicolumn{7}{|l|}{ Control variable } \\
\hline Earning profit & $0.127 \dagger$ & $-0.146^{*}$ & -0.097 & 0.048 & $-0.217^{*}$ & -0.057 \\
\hline Size of Enterprise & 0.231 & -0.233 & 0.044 & 0.155 & $-0.785 * * *$ & -0.086 \\
\hline Time of enterprise establishment & $0.152 *$ & -0.046 & $0.197^{*}$ & $-0.173 *$ & $0.178^{*}$ & $0.152 * *$ \\
\hline Profit & $0.587 * * *$ & $-0.36 * * *$ & 0.008 & 0.116 & $-0.212 *$ & $0.26 * * *$ \\
\hline Operating scale & $-0.5 * *$ & $0.613 * * *$ & -0.116 & $-0.58 * *$ & $0.3 \dagger$ & -0.08 \\
\hline \multicolumn{7}{|l|}{ Dependent variable } \\
\hline National inertia & -0.06 & -0.086 & 0.184 & 0.278 & -0.177 & -0.056 \\
\hline Regional inertia & $0.272 *$ & $-0.424 * * *$ & $0.474 * *$ & 0.051 & $-0.54 * * *$ & -0.085 \\
\hline National complexity degree & $0.1 \dagger$ & $-0.19 \dagger$ & 0.168 & 0.113 & -0.057 & -0.008 \\
\hline Regional complexity degree & 0.107 & -0.124 & 0.148 & 0.106 & -0.122 & 0.036 \\
\hline Operating expense ratio & & & & & & $-0.873 * * *$ \\
\hline Sales expense ratio & & & & & & $-0.239 * *$ \\
\hline Management expense ratio & & & & & & $-0.257 * * *$ \\
\hline Financial expense ratio & & & & & & $-0.209 * *$ \\
\hline R square & 0.571 & 0.63 & 0.28 & 0.381 & 0.454 & 0.845 \\
\hline F & $13.625 * * *$ & $17.394 * * *$ & $3.973 * * *$ & $6.279 * * *$ & $8.516^{* * *}$ & $36.997 * * *$ \\
\hline
\end{tabular}

a. ***. Regression is significant at the 0.001 level (2-tailed).

b. **. Regression is significant at the 0.01 level (2-tailed).

c. *. Regression is significant at the 0.05 level (2-tailed)

d. $†$. Regression is significant at the 0.1 level (2-tailed)

In addition, most Western scholars believe that the ultimate goal of M\&A is to achieve financial or investment synergy [19], and that financial synergy can promote enterprises to create competitive advantage [20]. However, based on the analysis results of this paper, we find that the degree of financial synergy is the smallest among the four synergistic dimensions $(0.209, p<0.0001)$, but the operational synergy has the greatest impact on firm performance $(0.873$, $\mathrm{p}<0.0001)$. This also reflects to some extent the resource orientation behind Chinese M\&A behavior [21, 22].

\section{REFERENCE}

[1] H.L. Lan, Study on Strategic behavior of Chinese enterprises in transformation. Guangzhou: South China University of Technology Press, 2007.

[2] X.Y. Cui, X. Lv, Y.J. Wei, S.Y. Wang, and H.X. Yin, “An Empirical Analysis of the Post-acquisition Performance of Consumer Electronic Information Enterprises: Exemplified by TCL Group," Management Review, vol. 29(11), pp. 251-260, 2017.
[3] C.D. Edwards, "Conglomerate bigness as a source of power," In Business concentration and price policy, Princeton: Princeton University Press, 1955, pp. 331-352.

[4] Z. Tian and S. Fan, "Competitive Interaction: A study of Corporate Market and Non-market Behaviors in Chinese Transitional Environment," Journal of Chinese Economic and Foreign Trade Studies, vol. 1(1), pp. 36-48, 2008.

[5] D.R. Gnyawali and R. Madhavan, "Cooperative Networks and Competitive Dynamics: A Structural Embeddedness Perspective," Academy of Management Review, vol. 26(3), pp. 431-445, 2001.

[6] S.X. Li and R. Greenwood, "The Effect of Within-industry Diversification on Firm Performance: Synergy Creation, Multi-market Contact and Market Structuration," Strategic Management Journal, vol. 25(6), pp. 1131-1153, 2004.

[7] W.J. Ferrier, K.G. Smith, and C.M. Grimm, "The Role of Competitive Action in Market Share Erosion and Industry Dethronement: A Study of Industry Leaders and Challengers," Academy of Management Journal, vol. 42, pp. 372-388, 1999.

[8] P.R. Nayyar and K.A. Bantel, "Competitive Agility: A Source of Competitive Advantage Based on Speed and Variety," Adv. Strategic Management, vol. 10A, pp. 193-222, 1994. 
[9] D.R. Gnyawali, J. He, and R. Madhavan, "Impact of Coopetition on Firm Competitive Behavior: An Empirical Examination," J. Management, vol. 32(4), pp. 507-530, 2006.

[10] D. Miller and M. Chen, "Sources and Consequences of Competitive Inertia: A Study of the U.S. Airline Industry," Administrative Science Quarterly, vol. 39: pp. 1-23, 1994.

[11] D.C. Hambrick, T.S. Cho, and M. Chen, "The Influence of Top Management Team Heterogeneity on Firms' Competitive Moves," Administrative Science Quarterly, vol. 41(4), pp. 659-684, 1996.

[12] K.G. Smith, C.M. Grimm, M.J. Gannon, and M. Chen, "Organization Information Processing, Competitive Responses Industry and Performance in the U.S. Domestic Airline," Academy of Management Journal, vol. 34, pp. 60-85, 1991.

[13] C.K. Prahalad and G. Hamel, "The Core Competence of the Organization," Harvard Business Review, vol. 68(May-June), pp. 7991, 1990.

[14] M. Chen and I. MacMillan, "Non-response and Delayed Response to Competitive Moves: The Roles of Competitor Dependence and Action Irreversibility," Academy of Management Journal, vol. 35, pp. 539-570, 1992.

[15] J.W. Busbin, J.T. Johnson, and J. DeConinck, "The Evolution of Sustainable Competitive Advantage: From Value Chain to Modular
Outsource Networking," Competition Forum, vol. 6(1), pp. 103-108, 2008.

[16] J. Downes and E.G. Jordan, Barron's Finance \& Investment Handbook ( $4^{\text {th }}$ ed). Hauppauge, NY: Barron's Educational Series, 1986.

[17] H.I. Ansoff, The New Corporate Strategy, NY: Wiley, 1988.

[18] M. Chen and D. Miller, "Competitive Attack, Retaliation and Performance: An Expectancy-valence Framework," Strategic Management Journal, vol. 15(2), pp. 85-102, 1994.

[19] M. Bradley, A. Desai, and E.H. Kim, "The Rationale Behind Interfirm Tender Offers: Information or Synergy?" Journal of Financial Economics, vol. 11, pp. 183-206, 1983.

[20] M. Alshamali, M. Alfadly, and N.I. Abumustafa, "Financial and Social Barriers to Bank Merger and Acquisition," Journal of Derivatives \& Hedge Funds, Vol. 14(3/4), pp. 160-197, 2008.

[21] H.B. Yang, S.L. Sun, and Z. Lin,"Behind M\&As in China and the United States: Networks, Learning, and Institutions," Asia Pacific Journal of Management, vol. 28(2), pp. 239-255, 2011.

[22] L. Fan, T. Wu, and Z. Zhai, "Relationship between Resource Relatedness and M\&A Success: Evidence from Firms in Chinese Manufacturing Industry,” Technology Economics, vol. 37(5), pp. 71-80, 2018. 